\title{
CLIMATE CHANGE AND INTERNATIONAL RELATIONS TOWARDS GREENER ENVIRONMENT IN THE WORLD
}

\author{
Dr. Binod Das
}

\section{$\boldsymbol{\&}$}

\section{Dr Mayuri H Pandya}

\section{$\underline{\text { Abstract }}$}

Climate change is a multi-dimensional global problem. Its causes and impacts are distributed and felt across the International system, surpassing the traditional boundaries and jurisdictions of the states. The complex politics of climate change results from the global economy's interdependence on green house gas emissions. This paper attempts to explore the politics of climate change between developed and developing countries, International relations practice and environment issues in various International conferences. The historical perspective of climate change issues deliberated since Stockholm conference to the latest Paris conference is analysed.

Adaptation, mitigation, finance, technology all these issues are highlighted in the paper. The paper has viewed that the International policy on environment is being shaped by inequality of bargaining power between the North and South. The developing countries under the leadership of India have taken firm position against the developed nations on the issue of green house gas emission, funding and technology, the paper has argued. Towards the end, this paper has focused on possible measures to address the problems of climate change through foreign policy initiatives, trade and investment, adaptation and mitigation.

Key Words - environment, climate change, foreign policy, north-south divide, climate investment.

\section{Introduction:}

Climate change is one of the greatest challenges of this century. Many feel that climate change has become an international problem affecting the international relations. This issue is making or breaking the relationship among the countries. Climate change has multifarious consequences. It 
impacts global issues, including poverty, economic development, population growth, sustainable development and resource management. The greenhouse gas emissions and impacts are distributed across the international system, transcending national boundaries. India, as a developing country is concerned about the adverse impact of climate change on its economy. A large part of its population depends on climate sensitive sectors for livelihoods which makes it highly vulnerable to climate change. Owing to the global dimensions, climate change is not only a threat to the environment but to global security and economic prosperity. It is also multidimensional, invisible and unpredictable.

Realising the global dimensions of climate change, the world leaders have deliberated in the past. The UN conference on the Human development organised in 1972 at Stockholm is considered as turning point in international relations. The conference internationalised the

environmental concerns and facilitated the establishment of the United Nation Environment Programme (UNEP). It worked as a catalyst in the growth of green movements and green politics in developed countries. Since then nation states are engaged in international deliberations for developing international protocols and creating international environmental regimes.

The Report of the World Commission on Environment and Development (1987) widely known as Brutndland Report ${ }^{1}$ looked at the dynamics of global environment concerns from the liberal and international perspectives. Besides, series of tragedies such as Minamata tragedy in Japan (1950s), Bhopal gas tragedy (1984), Chernobyl disaster (1986) have raised environment problems.

Many studies have been undertaken on climate change and international relations. Sosa $(2016)^{2}$ in the edited collection explained complex relationship between international relations, environment and climate change. It explores the most important routes of assessing environmental issues as an issue of international governance and provides perspectives on the route forward.

\footnotetext{
${ }^{1}$. Brutndland Report- http://www.sustainabledevelopment2015.org/AdvocacyToolkit/index.php/earth-summit-istory/historicaldocuments/92-our-common-future (Accessed on April 18, 2017)

${ }^{2}$ Gustavo, Sosa-Nunez \& Ed, Atkins (ed.), Environment, Climate Change and International Relations, International Relations Publishing, England, 2016
} 
Habib $(2011)^{3}$ in the paper climate change and international relations theory explored the broader relationship between climate change and international relations theory. The paper has examined the Northeast Asian political environment from the perspective of three international relations theories realism, liberalism and constructivism.

This paper has attempted to eexplore the climate change issues which are governing the relations between the countries, ascertain India's position on climate change issues vis-à-vis other countries and suggest policy recommendations for the relationship of the country on climate change issues. The study is based on the provisional supposition that climate change will be major contentious issue between the countries.

\section{Past of Climate Change and International Relations}

Historically, the politics of climate change dates back to several conferences in the late 1960s under NATO and President Richard Nixon. The year 1979 saw the world's first World Climate Conference. Vienna convention for the protection of the ozone layer was created in 1985 and two years later saw the signing of the Montreal Protocol under the Vienna convention.

One year later in 1988 the Intergovernmental Panel on Climate Change was created by the United Nations Environment Programme to assess the risk of human-induced climate change. Margaret Thatcher 1988 strongly supported IPCC and 1990 was instrumental to found the Hadley Centre for Climate Prediction and Research in Exeter. ${ }^{4}$ The United Nations Framework Convention on Climate Change (UNFCCC) was agreed at the Earth Summit in Rio de Janeiro in 1992 and the framework entered into force in 1994.

1997 saw the creation of the Kyoto Protocol under the United Nations Framework Convention on Climate Change (UNFCCC). Developing countries have grown significantly with China replacing the United States as the largest emitter of greenhouse gases. To some the UNFCCC has made significant progress in helping the world become aware of the perils of global warming and has

\footnotetext{
${ }^{3}$ Habib, Benjamin (2011), Climate Change and International Relations Theory: Northeast Asia as a Case Study, paper presented in the Global International Studies Conference, University of Porto, Portugal, August 2011,

${ }^{4}$ Malhotra, V. K. (2014), International Relations, $4^{\text {th }}$ Edition, New Delhi.
} 
moved the world forward in the addressing of the challenge. To others the UNFCCC process has been a failure due to its inability to control the rise of greenhouse gas emissions.

As part of the 2010 Cancun agreements, ${ }^{5}$ nearly 76 developed and developing countries have made voluntary pledges to control their emissions of greenhouse gases. These voluntary steps are seen by some as a new model where countries voluntarily take action against global warming of international treaties. This voluntary mechanism, does not address challenges faced by the developing world in their efforts to mitigate global warming.

The UN conference on the human development organised in 1972 at Stockholm is considered as turning point in the development of international relations. The conference was the starting point for internationalising environmental concerns. Since 1970s global meets have been undertaken. The major meetings are Stockholm Conference (1972), World Climate Conference (1979), Montreal Protocol (1987), Inter-governmental Panel of Climate Change (1988), The Rio Summit (1992), Kyoto protocol (1997), World Summit on Sustainable Development (2002), Bali Conference (2007) and Paris Conference (2015). The development in the conferences are described below.

1988 IPCC: The United Nations set up the on Climate Change (IPCC) in November 1988. The IPCC's role was to publish reports that provide a clear and up-to-date picture of the current state of scientific knowledge relating to climate change.

1992 Rio Earth Summit: The international community launched fight against climate change in June 1992 in Rio de Janeiro, Brazil, at the second Earth Summit. Following the conference, 166 countries signed the United Nations Framework Convention on Climate Change (UNFCCC), which acknowledged humanity's role in global warming. The earth summit adopted Rio declaration and blue print for sustainable development. ${ }^{6}$

1997 Kyoto Protocol: This international emission reduction agreement was adopted on December 11, 1997, at the third Conference of the Parties in Kyoto, Japan. The goal was to reduce emissions

\footnotetext{
${ }^{5}$ The Cancun Agreement (2010) is a set of significant decisions by the international community to address the challenge of climate change and take concrete action to speed up the global response. The agreement captured plans to reduce greenhouse gas emissions and to support developing nations to protect themselves from climate impacts.

${ }^{6}$ UN Conference on Environment and Development (www. http://www.un.org/geninfo/bp/enviro.html) (accessed on April 18, 2017)
} 
of six greenhouse gases by 5.2 per cent between 2008 and 2012. An international carbon market was established to help achieve this goal.

2005 European Union Emissions Trading System: In January 2005, the European Union launched emissions trading scheme. In December 2008, the European Union adopted series of legislative measures, which laid down three targets for 2020.

2009 Copenhagen Climate Change Conference: The parties to the UNFCCC met in Copenhagen in December 2009 to forge a new agreement to succeed the Kyoto Protocol. The Copenhagen conference defined the acceptable increase in global temperature as $2{ }^{\circ} \mathrm{C}$ above pre-industrial levels. However, the countries failed to reach an agreement on greenhouse gas emission reduction targets.

2015 Paris Agreement: The Paris agreement was a pragmatic deal that ensured countries accountable and built ambitions. Core elements of the agreement included commitments on emissions, adaptation, finance, transparency and steps to promote carbon trading. The Paris Agreement united all nations into a common cause to combat climate change and adapt to its effects, with the support of developed countries.

The focus of the climate change conference varied from time to time. However, all the conferences attempted to strengthen the ability of countries to deal with the impacts of climate change. Appropriate financial flows, a new technology framework and an enhanced capacity building framework were put in place to reach these ambitious goals. Additionally, countries agreed to undertake transparency of action and support through a more robust transparency framework. Sustaining the efforts, United Nations Framework Convention on Climate Change (UNFCC) is scheduled to organise the climate change conferences in 2017.

\section{India's Stand on Climate Issues}

The idea of environmental conservation was built into India's traditional culture. India has been ranked at a low $155^{\text {th }}$ position in a global list that places countries on how well they perform on high-priority environmental issues. ${ }^{7}$ India is the fourth largest (GHG) emitter, emitting 5.8 per cent of global emissions. India's emissions are 70 per cent below world average and 93 per cent below US average. This signifies the onus of emission reduction lies with the developed countries. India recommends that emission reduction is consistent with the carbon space that nation occupies. Again, even if the first commitment has not been achieved, the developed world should ratify Kyoto's second commitment by 2020. On the contrary, developing countries will begin voluntary carbon emission reduction after 2020, India opined. India accepted in principle the

\footnotetext{
${ }^{7}$ Poornima, Sharat (2015), Climate Change in India: Challenges and Solutions, Mainstream, VOL LIII No 50 New Delhi, December 05 .
} 
voluntary commitment of carbon reduction, termed as Intended Nationally Determined Contribution (INDC) ${ }^{8}$. India also demanded 100 billion dollar assistance from the rich to poor nations by 2020 and recommended formation of solar alliance by solar energy rich countries similar to OPEC $^{9}$. India also felt that private financing in energy goals and carbon taxation should be ensured.

India is the primary leader of the G- $77^{10}$ countries, mostly the developing nations. Presently, 134 countries are members of the Group-77. These countries will be influenced by the activities of India. Thus, India's role in climate change issue has high significance. Other developing countries will definitely endorse India's position. US-India will take similar stand on the issue due to growing friendship and bonhomie between the countries. India talks of climate justice, which is acceptable to all the countries.

India has the developmental needs such as poverty reduction, health, energy access and education. Higher energy production and consumption is a driving force of economic development and poverty reduction. India cannot ignore the developmental needs to address the green house gas emissions.

In the Paris Climate Conference, India asked the rich nations to approve the second commitment period of the Kyoto Protocol ${ }^{11}$. The first commitment period of the Kyoto Protocol ended in 2012 and major emitters withdrew from the commitment due to domestic political compulsions. ${ }^{12}$ Thus, the onus of mitigation fell on the western countries, Indian reminded the major emitters in Paris conference. India argued that the developed countries must fulfil their responsibility to make clean energy affordable and accessible to all in the developing world. India wanted the 100 billion dollar a year plan for assistance from the rich to poor nations by 2020 must be expedited.

So far, India has refused to consider limiting its own carbon emissions. Successive Indian governments have maintained that expanding access to energy, not reducing emissions, must be the country's priorities. India has repeated this stand, implying that India would not limit its emissions in near future but will undertake every major to reduce carbon emissions.

\footnotetext{
${ }^{8}$ Intended Nationally Determined Contributions (INDCs) is a term used under the United Nations Framework Convention on Climate Change (UNFCCC) for reductions in greenhouse gas emissions by all the signatories of UNFCCC.

${ }^{9}$ The Organization of the Petroleum Exporting Countries (OPEC) was founded in Baghdad, with the signing of an agreement in September 1960 by five countries namely Islamic Republic of Iran, Iraq, Kuwait, Saudi Arabia and Venezuela. These countries were later joined by Qatar (1961), Indonesia (1962), Libya (1962), the United Arab Emirates (1967), Algeria (1969), Nigeria (1971), Ecuador (1973), Gabon (1975) and Angola (2007). Currently, the Organization has a total of 13 Member Countries.

10 The Group of $\mathbf{7 7}$ (G-77) was established on 15 June 1964 by signatories of the "Joint Declaration of the Seventy-Seven Developing Countries" issued at the United Nations Conference on Trade and Development (UNCTAD) in Geneva.

11 The Kyoto Protocol legally binds developed countries to emission reduction targets. The Protocol's first commitment period started in 2008 and ended in 2012. The second commitment period began on 1 January 2013 and will end in 2020.

${ }^{12}$ Malhotra, V. K. (2014), International Relations, $4^{\text {th }}$ Edition, New Delhi.
} 
In the developing world, climate change partnerships have been developed with emerging economies such as Brazil, India, China, South Korea and South Africa. The European Commission (EC) also interacted with number of regional groupings on environment and climate change issues such as the African, Caribbean and Pacific (ACP) countries, Asia Europe Meeting (ASEM), the Association of South East Asian Nations (ASEAN), the Gulf Cooperation Council (GCC), Latin American and Caribbean (LAC) countries and the Organisation of the Petroleum Exporting Countries (OPEC). This signifies EC's interaction with many countries on climate change issues.

\section{Climate Change and Contentious Issues}

Climate change issue has become a major contention between various countries. The issues are many. First, all the countries agree that greenhouse-gas emissions which drive warming must be curbed. The UN has endorsed a ceiling of two degrees Celsius over the pre-industrial levels. But small-island states such as Barbados, Fiji and Maldives which are highly vulnerable to climate change favour a tougher goal of 1.5 degree Celsius instead of 2 degree Celsius. Second, in the last two decades, situation has changed a lot. China and India has become the world's number one and four carbon emitters respectively. The developing countries have scaled the economic ladder and the European Union and United States have slowed their carbon emissions. Thus the earlier major emitters are no longer main polluters. Third, 2009 UN climate conference in Copenhagen pledged annual 100 billion dollars financial support for the poor countries, starting from $2020 .{ }^{13}$ Some part of the fund will be utilised by the developing countries to adopt technology to curb their emissions. The remaining will be earmarked for measures to adapt climate change impacts like rising seas and spreading deserts. The contentions emerged regarding source and distribution of fund. Lastly, least-developed countries and small-island and developing states presented an additional demand for compensation for climate loss and damage. These demands have created a rift between rich and poor nations. Besides, differences have emerged on many operational issues. However, contentions are noticed on global environmental problems, divergent views on environmental concern and politicisation of environmental issues.

North-South Divide: The northern countries represent the countries located in northern hemisphere, mostly rich and the developed countries and southern countries, located in southern hemisphere, are of the poor and underdeveloped countries of Asia and Africa. Differences have emerged in these two groups. Environment debate in different international forums and conferences witnessed the north-south divide and hierarchy. Disagreements between north and south weighed their agreements on the matter of global environmental problems. While some

\footnotetext{
${ }^{13}$ https://phys.org/news/2015-11-climate-contention.html (accessed on April 24, 2017)
} 
perceive the under-development of third world countries itself as major cause of environmental damage, many advocates argue that the process of development along the lines of industrial progress has been instrumental in environmental negotiation. Developing countries demand that developed countries should support the replacement of polluting industrial of the south. Fixing responsibilities for global environment credit like ozone layer depletion, green house emissions etc and paying for measures to tackle these global problems are still contentious issues between north and south. The north-south differences also exist on bio-diversity conservation and use.

Divergent Views of Developed Countries: Even the developed countries have divergent views on many environmental issues. For example the tough stand against carbon dioxide emission by European states was due to awakening. Moreover growth of green parties in more than two thirds of European Union (EU) countries including Germany, Austria, Sweden, Belgium, Finland, Italy, France and Netherland worked as catalyst in Europe. ${ }^{14}$ However, US opposed the tough stand taken by EU countries due to its position as the largest producer of coal, oil and gas. Similarly, OPEC countries opposed any curtailment of these resources, whereas Alliance of the Small Island States (AOSIS) ${ }^{15}$ countries such as Bahamas, Barbados, Cuba, Dominica and Singapore demanded high emission reductions.

Politicization of Environmental Issues: The environmental negotiation gradually became politicized in the 1990s. Political parties emerged in Europe highlighting the environmental concerns The European Green Party cooperated with the European Free Alliance (EFA) to form the Greens - European Free Alliance parliamentary group in the European parliament. During this period, the controversy emerged between the developed and developing countries, especially regarding the measures to mitigate the impact. The developed states viewed that climate change is a common technological and economic problem and it is caused by green house gas emission. It could be tackled by providing encouragement of new technology in the developing states. On the other hand, developing states viewed that climate change is a western problem. It is caused by

\footnotetext{
${ }^{14}$ Oberthur Sebastian and Herrmann, Ott. E. (1999), The Kyoto Protocol International Climate Policy for the $21^{\text {st }}$ Century, Berlin, Heidberg: Springer-Verlag.

15 The Alliance of Small Island States (AOSIS) is a coalition of Small Island and low-lying coastal countries that share similar development challenges and concerns about the environment, especially their vulnerability to the adverse effects of global climate change.
} 
consumption pattern. It cannot be dealt with without looking into problems inherent in the developing paradigm and at distribution issues such as who is entitled to what emission. ${ }^{16}$

\section{Recommendations}

Climate change mitigation measures limit the rate of long-term climate change. Mitigation policies can substantially reduce the risks associated with human-induced global warming. The mitigation measures include phasing out fossil fuels by switching to low-carbon energy sources and expanding forests to remove carbon dioxide from the atmosphere. Energy efficiency may also play a role through improving the insulation of buildings. Similarly, another approach to climate change mitigation is climate engineering. ${ }^{17}$ Moreover, the following measures can be undertaken to further strengthen international relations.

\section{Partnership for Energy Security and Investment}

India's per capita energy consumption is the lowest among all the major developing economies in the world. Though, this can be attributed to the service economy, it holds true even when India is compared to countries such as Brazil, Argentina and Mexico that have a GDP (Gross Domestic Product) similar to that of India. ${ }^{18}$ The fact is that India's rural population is largely dependent on non-commercial sources of energy. As the urbanisation is increasing, the energy demand is set to go up significantly. This situation is providing partnership for energy security and investment. India must attract new investment on energy security. This will boost the economy and address green house gas emission. Energy Security can be achieved in the areas of clean energy, renewable energy and energy efficiency.

\section{Climate issues in foreign policy}

There is an increasing realization in the international community that achieving the consensus and commitment needed to take action requires positioning climate change in a broader foreign policy context. Climate change is not only a threat to the environment but to global security and economic prosperity. A study ${ }^{19}$ undertaken by G-77 says climate change is the ultimate threat multiplier posing serious risk to world security. Tackling climate change risks must become a top foreign policy priority in the $21^{\text {st }}$ century. The study, citing social conflicts in Syria

\footnotetext{
${ }^{16}$ Gupta, Joyeeta (1997), The Climate Change Convention and Developing Countries from Conflict to Consensus, Netherlands: Kulwer

17 "Sec 5.5 Technology flows and development", Climate Change 2007: Synthesis Report, in IPCC AR4 SYR 2007

${ }^{18}$ It's our turn now E\&P partnership for India's energy security, 2012, www.pwc.com/india (Accessed on April 19, 2017)

${ }^{19}$ Guardian, https://www.theguardian.com/environment/2015/jun/24/g7-climate-change-global-warming-top-foreign-policypriority-study (Accessed on April 27, 2017)
} 
and Mali and land grabs in Ethiopia, warned that problems aggravated by climate change - such as food insecurity, water scarcity, migration and displacement. India has already streamlined energy decision-making and also environmental decision-making. Internationally, India has taken a new low-carbon approach to development - and in the process to demonstrate that India can be a global environmental leader without sacrificing economic growth.

\section{Address mitigation and adaptation through trade and investment}

Trade and investment liberalization provide the means to address mitigation and adaptation. Countries can use this opportunity. Addressing climate change will require global investment and financial flows. While the changes appear large in absolute terms, they are small relative to total investment. Most of the changes and additional investment are likely to be made by corporations and households, although this may require government policies and incentives. But additional public sector investment and financial flows will be required, especially for adaptation. Approximately, half of the shifts and net increase in investment and financial flows needed to address climate change occur in developing countries. Mitigation investments in developing countries are more cost-effective because larger emission reductions can be generated per dollar invested. On the other side, on average, developing countries are expected to suffer more damage from climate change impacts as a percentage of their Gross Domestic Product (GDP) in comparison to developed countries. Investments in planned adaptation should reduce the amount of damage experienced by developing countries and, therefore, should yield proportionately larger economic benefits.

\section{Conclusion}

Climate change has become an international problem affecting the relations among countries. The politics of climate change has started since 1980s, particularly in Europe. Since then global meets were convened to deliberate on environmental problems. The division between developed and developing nations was visible in the global meets. The developed nations were primarily responsible for high emission of green house gas. Thus one of reducing green house gas lies with the developed nations. Again the developing nations are suffering the effects of climate change. India as a leader of developing nations should unite developing countries and take a firm stand against counters responsible for high emission of green house gas. The Paris accord 2015 sets the architecture for carbon emission reduction after 2020. This principle puts the major responsibility on developed nations to drastically cut their carbon emissions and provide finance, technology and capacity building for developing economies to mitigate and adapt to climate change.

The Paris accord has voluntarily put the national pledge for reducing carbon emissions. China, United States and the European Union, which together account for more than half of global greenhouse emission have already submitted their targeted plans for greenhouse gas emissions. 
Scientists view the present global commitment is unlikely to meet the two degree Celsius objective. Many developing countries, including India, have refrained from any commitment to reduce the carbon emission. As a result, the target of achieving the carbon reduction emission has become improbable.

India has already created new platform for solar energy rich countries, particularly African countries, China and Japan. These countries should jointly bargain with the western countries and extract a commitment for emission reduction and financial support to address the climate change induced disasters.

Opportunities are presented by international diplomacy to further climate change objectives. While undertaking diplomacy, India must seek commonality with countries on climate issues. India should strongly advocate climate change issues in its foreign policy. Besides, trade policy can be integrated with climate change issues. In order to do this, strong political leadership and strategic engagement is required. To sum up, India is emerging as an economic power; India should use the power to address the climate change issues of all the developing countries.

\section{Dr. Binod Das}

Assistant professor, GLS Law College
$\&$

Dr Mayuri H Pandya

Director I/C

GLS Law College 